Arq. Bras. Med. Vet. Zootec., v.71, n.1, p.151-159, 2019

\title{
Alterações fisiológicas e comportamentais de bovinos de corte após o manejo de castração
}

\author{
[Physiological and behavioral changes of beef cattle after castration management] \\ C.C. Domingues ${ }^{1}$, O.S. Teixeira ${ }^{2}$, J. Cattelam ${ }^{3}$, M.B. Silva ${ }^{1}$, A.F. Moura ${ }^{1}$, \\ G.S. Cardoso ${ }^{1}$, I.L. Brondani ${ }^{1}$, D.C. Alves Filho ${ }^{1}$ \\ ${ }^{1}$ Universidade Federal de Santa Maria - Santa Maria, RS \\ ${ }^{2}$ Universidade Federal do Rio Grande do Sul - Porto Alegre, RS \\ ${ }^{3}$ Universidade Federal da Fronteira Sul - Realeza, PR
}

\begin{abstract}
RESUMO
Objetivou-se avaliar o desempenho, parâmetros fisiológicos e temperamentais de bovinos de corte não castrados ou submetidos à castração cirúrgica ou à imunocastração. O período experimental foi dividido em dois subperíodos de observações: primeiros 15 dias pós-castração (período de cicatrização) e os 25 dias seguintes à cicatrização. Nos primeiros 15 dias de avaliação, os animais não castrados obtiveram maior ganho médio diário de peso em relação aos castrados cirurgicamente. A frequência cardíaca foi maior para os animais castrados cirurgicamente, com 126,51 batimentos/minuto, em relação aos demais tratamentos. A distância de fuga foi superior para os novilhos castrados cirurgicamente, com valor de 12,22 metros. Nos 25 dias seguintes à castração cirúrgica, o ganho médio diário de peso foi superior nos bovinos castrados cirurgicamente em relação aos bovinos não castrados ou imunocastrados. A velocidade de fuga, no segundo subperíodo de avaliação, foi superior nos bovinos castrados em relação aos não castrados. O período imediato à castração, os primeiros 15 dias, prejudicou o ganho médio diário e o ganho de peso total, o que causou maior reatividade, com alterações nos parâmetros fisiológicos e temperamentais de bovinos castrados cirurgicamente em comparação com bovinos não castrados, entretanto, transcorrido o período de cicatrização, essas diferenças diminuíram ou desapareceram.
\end{abstract}

Palavras-chave: castração cirúrgica, desempenho animal, distância de fuga, imunocastração

\begin{abstract}
The aim of this study was to evaluate the performance, physiological and temperamental parameters of uncastrated beef cattle or those submitted to surgical castration or immunocastration, in the postcastration period. The experimental period was divided into two subperiods of observations: the first 15 days post-castration (healing period) and the 25 days following healing. In the first 15 days of evaluation, the non-castrated animals obtained a greater average daily gain of weight in relation to surgically castrated. The heart rate was higher for surgically castrated animals with 126,51 beats/minute, compared to the other treatments. The distance of escape was higher for the surgically castrated steers, with a value of 12,22 meters, when compared to the other groups studied. During the next 25 days of surgical castration, the mean daily gain of weight was higher in surgically castrated cattle than in non-castrated or immunocastrated cattle. The escape velocity, in the second evaluation subperiod, was superior in the castrated cattle, in relation to the not castrated. The immediate castration period, the first 15 days, altered the mean daily gain and the total weight gain, the physiological and temperamental parameters of surgically castrated cattle, however, after the healing period, these differences diminish or disappear.
\end{abstract}

Keywords: animal performance, flight distance, immunocastration, surgical castration

Recebido em 10 de janeiro de 2018

Aceito em 2 de julho de 2018

E-mail: camidomingues1@gmail.com 


\section{INTRODUÇÃO}

A castração de machos é uma prática rotineira em fazendas que criam bovinos de corte, sendo realizada com o intuito de facilitar o manejo dos animais (Matta et al., 2017). Coetzee (2013) ressalta que a castração contribui para maior docilidade, suprime distúrbios de conduta sexual e não permite acasalamentos indesejados em bovinos. Além disso, Moletta et al. (2014) enfatizam que esse procedimento favorece a qualidade da carcaça e da carne, ao produzir animais com maior espessura de gordura e, consequentemente, melhor acabamento no abate em relação a bovinos não castrados.

Quanto ao método de castração, há discussões nos diferentes sistemas de criação de bovinos, portanto as circunstâncias e as preferências devem ser consideradas pelo gestor rural na escolha da técnica. Isso porque existem vários processos de castração, como a castração cirúrgica, a mais utilizada mundialmente, a química, a com burdizzo, a imunocastração e a castração utilizando anéis de borracha, esta última proibida no Brasil (Brasil, 2008). Cada uma com vantagens e desvantagens, principalmente relacionadas à pós-castração, as quais são de grande importância, pois influenciam diretamente todo o processo produtivo (Lazzeri, 1994).

Assim, deve-se optar por métodos que resultem no mínimo de complicações pós-castração, em menor estresse ao animal e, consequentemente, em menor perda de peso na fase de recuperação, pois a castração pode causar sofrimento e, em casos mais graves, a morte dos animais. Diante disso, tem-se como opção a castração imunológica, vacina anti-GnRH (fator liberador de gonadotrofinas) para uso em bovinos fora do período reprodutivo. Essa vacina, anti-GnRH, induz a produção de anticorpos neutralizantes, resultando em imunocastração mediante a supressão do hormônio luteinizante e da testosterona (Geary et al., 2011).

Por meio de melhores práticas de castração, busca-se reduzir o estresse dos animais, o qual se caracteriza pela soma de mecanismos de defesa do animal a algum agente estressor, que pode ser elucidado como incorretas práticas com bovinos: manejo aversivo, práticas cirúrgicas sem os devidos cuidados ou violação dos protocolos de bem-estar animal (Ferreira et al., 2006). Com base nesse conhecimento, surge a preocupação da quantificação do estresse, na produção animal, a qual tem recebido atenção do público em geral nos últimos anos (Silva et al., 2014).

Portanto, por meio da etologia, podem-se compreender as respostas dos bovinos diante de diferentes situações de manejo e, dessa forma, atender as necessidades dos animais, a fim de se alcançar a redução da sua reatividade, com impactos positivos na relação humano-animal e também animal-ambiente, para, assim, obter melhora na eficiência produtiva. $\mathrm{O}$ objetivo deste estudo foi avaliar o desempenho e os parâmetros fisiológicos e temperamentais de bovinos de corte castrados cirurgicamente ou imunologicamente, comparando-os aos animais não castrados.

\section{MATERIAL E MÉTODOS}

A Comissão de Ética no Uso de Animais da Universidade Federal de Santa Maria aprovou todos os procedimentos que envolveram animais, sob o protocolo $\mathrm{n}^{\mathrm{o}} 122 / 2014$. O experimento foi conduzido no Laboratório de Bovinocultura de Corte (LBC) do Departamento de Zootecnia da Universidade Federal de Santa Maria, situado no município de Santa Maria, no estado do Rio Grande do Sul.

O período experimental compreendeu os meses de novembro e dezembro, totalizando 40 dias, divididos em dois subperíodos de observações: o primeiro compreendeu 15 dias, e o segundo 25 dias. A área experimental total utilizada correspondeu a 8,04ha de capim-aruana (Panicum maximum Jacq. cv. Aruana), implantada no ano de 2012. Essa área foi dividida em 12 piquetes de áreas semelhantes, com 0,67ha cada, nos quais permaneceram os animais testes. A massa de forragem foi de $2600 \mathrm{~kg} \mathrm{MS} \mathrm{ha}{ }^{-1}$; para isso, foi utilizado o sistema de lotação contínua, com número variável de animais reguladores, por meio da técnica Put-and-take (Mott e Lucas, 1952).

Foram utilizados 39 bovinos machos, com peso corporal e idade iniciais médios de $270,14 \mathrm{~kg}$ e 12 meses, respectivamente. Os animais foram divididos em grupos de bovinos castrados cirurgicamente, imunocastrados ou não 
castrados. Eles eram oriundos do cruzamento alternado contínuo entre as raças Charolês e Nelore. Previamente ao início do estudo, todos os animais passaram pelo tratamento com parasiticida injetável, tendo com princípio ativo abamectina a $1 \%$, na dosagem $1 \mathrm{~mL} 50 \mathrm{~kg}^{-1}$ de peso vivo. A castração cirúrgica foi realizada por médicos veterinários, os quais utilizaram a técnica de orquiectomia aberta por remoção do ápice da bolsa escrotal, com uso de bisturi (lâmina $\mathrm{n}^{\circ}$ 24). Anteriormente ao ato cirúrgico, os animais foram contidos no tronco e foi realizada a higienização da bolsa escrotal com álcool etílico de concentração $70 \%$.

Os fármacos utilizados no procedimento cirúrgico basearam-se na combinação de anestésico local, por meio do bloqueio com lidocaína, na dosagem de $7 \mathrm{~mL}$, em cada cordão espermático, e anti-inflamatório de princípio ativo flunixina meglumina, na dosagem de $1,1 \mathrm{mg} \mathrm{kg}^{-1}$, via intramuscular. Webster et al. (2013) recomendam essa combinação de fármacos, pois identificaram menor estresse nos bovinos castrados, quando se utilizaram esses medicamentos, medido pelos níveis do hormônio cortisol no sangue. Além desses medicamentos citados, também foi aplicado antibiótico com princípio ativo oxitetraciclina, na dosagem de $1 \mathrm{~mL}$ para cada $10 \mathrm{~kg}$ de peso vivo dos bovinos. $\mathrm{O}$ antibiótico e o antiinflamatório foram administrados no dia da castração e no segundo, quarto e sexto dias após a castração, juntamente com uso de spray cicatrizante repelente no local da incisão cirúrgica.

O método de imunocastração consistiu em duas doses de vacina que inibe o fator liberador de gonadotrofinas. Os animais pertencentes a esse tratamento receberam a primeira dose aos 11 meses de idade, a segunda com 12 meses, conforme o protocolo de aplicação da vacina, a qual foi administrada pelo técnico reconhecido pela companhia fabricante do produto. Preconizou-se que as castrações (cirúrgica e imunocastração) fossem realizadas concomitantemente, a fim de comparação entre os tratamentos, sendo efetuada aos 12 meses de idade dos novilhos, pois, a partir desse mês, os animais imunocastrados foram considerados castrados.

Nos dias de aplicação dos fármacos e no $15^{\circ}$ e $40^{\circ}$ dias pós-castração, foram realizadas as mensurações dos parâmetros fisiológicos e comportamentais dos animais, utilizando-se o centro de manejo como ambiente de mensuração. $\mathrm{O}$ manejo era realizado por pessoas treinadas, obedecendo aos princípios do comportamento e bem-estar dos animais. As variáveis mensuradas foram medidas fisiológicas: audibilidade cardíaca e respiratória, bem como as temperamentais, que indicam a reatividade dos animais: escore composto de balança, velocidade de fuga e distância de fuga; essas avaliações foram realizadas no centro de manejo. Para a aferição da frequência cardiorrespiratória, os animais eram contidos no tronco de contenção, e, por meio do aparelho estetoscópio, posicionado na região torácica esquerda, contabilizavam-se a frequência respiratória e os batimentos cardíacos por minuto.

$\mathrm{Na}$ avaliação do escore composto de balança, atribuía-se o escore após 10 segundos da entrada do animal na balança. Os escores compostos de balança foram nomeados: 1= animal calmo, nenhuma respiração audível; $2=$ animal inquieto, alternando a posição das patas; $3=$ animal se contorcendo, tremendo, movimentando ocasionalmente a balança, respiração audível ocasional; $4=$ animal com movimentos contínuos e vigorosos, movimentando a balança, respiração audível; 5= animal com movimentos vigorosos e contínuos, movimentando a balança, virando-se ou lutando violentamente, respiração audível; adaptado da metodologia de Piovezan (1998).

Para a mensuração da velocidade de fuga, registrou-se, com o uso de cronômetro, o tempo gasto pelo animal para percorrer a distância de $5,5 \mathrm{~m}$ após a abertura da porteira da balança. $\mathrm{O}$ quociente entre a distância percorrida e o tempo gasto no percurso representou a velocidade de fuga (Piovezan, 1998). Depois de os animais saírem da balança, eles eram direcionados a um curral, no qual se respeitava o tempo que o animal levava para se acalmar e, então, procedia-se à última avaliação de reatividade: o teste de distância de fuga. Nesse teste, considerou-se a distância mínima em que o animal permite a aproximação do ser humano sem se deslocar, ou seja, o observador tentava aproximar-se do animal, interrompendo-se quando o animal se desloca (Boivin et al., 1992). O teste de distância de fuga foi realizado 
em curral, com piso de terra, com dimensão de $34,0 \mathrm{~m}$ de comprimento $\mathrm{x} 11,0 \mathrm{~m}$ largura $\mathrm{x} 1,75 \mathrm{~m}$ de altura.

O acompanhamento do desempenho animal foi realizado mediante pesagens dos animais por período, feitas no dia da castração, no $15^{\circ}$ dia imediatamente à castração e no $40^{\circ}$ dia após a castração. Assim, o ganho médio diário dos animais foi calculado pela diferença de peso entre as pesagens, dividido pelo número de dias do período.

Previamente ao estudo, os animais foram balanceados por predominância genética e peso corporal, sendo mantidas as mesmas condições nutricionais, sanitárias e ambientais. Foi utilizado o delineamento inteiramente ao acaso, com três tratamentos e subperíodos divididos no tempo. Os dados coletados foram testados quanto à normalidade pelo teste de Kolmogorov-Smirnov, sendo realizados os ajustes quando necessário, por meio da transformada logarítmica, quando não apresentaram normalidade, como a variável ganho de peso total nos primeiros 15 dias, ou utilizando o teste de Kruskal-Wallis. Posteriormente, foram submetidos à análise de variância e ao teste $\mathrm{F}$, pelo procedimento PROC MIXED, para as variáveis de comportamento social, e PROC GLM, para as variáveis relacionadas ao desempenho, com $\mathrm{P}<0,05$. Quando observada diferença nas variáveis analisadas, as médias foram comparadas pelo teste $\mathrm{t}$ de Student, em nível de $5 \%$ de significância. Para todas as análises dos dados foi utilizado o pacote estatístico SAS (Statistical Analysis System, versão 9.2).

\section{RESULTADOS E DISCUSSÃO}

O peso inicial dos bovinos, nos primeiros 15 dias pós-castração, foi semelhante entre as condições sexuais avaliadas (Tab. 1), devido ao fato de os animais terem sido equiparados por peso e serem contemporâneos, com idades próximas ao início do experimento. O peso final dos animais 15 dias após a castração também foi similar, sendo esse associado ao tempo reduzido entre a castração e a avaliação do desempenho.

Tabela 1. Média e erro-padrão do desempenho de bovinos castrados cirurgicamente, imunocastrados e não castrados, nos primeiros 15 dias pós-castração

\begin{tabular}{lcccc}
\multicolumn{1}{c}{ Variáveis } & \multicolumn{3}{c}{ Condição sexual } & \multirow{2}{*}{ Valor P1 } \\
\cline { 2 - 4 } & Castrado & Imunizado & Não castrado & \\
\hline Peso inicial, $\mathrm{kg}$ & $274,73 \pm 8,29$ & $265,73 \pm 7,73$ & $269,97 \pm 7,34$ & 0,7350 \\
Peso final, kg & $280,04 \pm 9,01$ & $273,31 \pm 8,28$ & $281,53 \pm 7,98$ & 0,7556 \\
Ganho de peso total, $\mathrm{kg}$ & $5,32 \pm 1,86^{\mathrm{b}}$ & $7,58 \pm 1,71^{\mathrm{ab}}$ & $11,57 \pm 1,65^{\mathrm{a}}$ & 0,0471 \\
Ganho médio diário, $\mathrm{kg}$ & $0,35 \pm 0,12^{\mathrm{b}}$ & $0,50 \pm 0,11^{\mathrm{ab}}$ & $0,77 \pm 0,11^{\mathrm{a}}$ & 0,0464 \\
\hline
\end{tabular}

${ }^{\mathrm{a}, \mathrm{b}}$ Médias seguidas por letras diferentes na linha diferem pelo teste $\mathrm{t}$ de Student $(\mathrm{P}<0,05) .{ }^{1} \mathrm{P}=\mathrm{Probabilidade}$.

Nos primeiros 15 dias após a orquiectomia, os bovinos não castrados obtiveram maior ganho de peso total, de $11,57 \mathrm{~kg}$ (Tab. 1), e os novilhos imunocastrados ficaram em posição intermediária, com $7,58 \mathrm{~kg}$, enquanto os castrados cirurgicamente apresentaram menor ganho de peso total, com valor de $5,32 \mathrm{~kg}$, acompanhando a diferença encontrada no ganho médio diário. Semelhantemente a este estudo, Carvalho et al. (2011) analisaram diferentes métodos de castração em quatro propriedades, por ablação ou incisão lateral da bolsa escrotal, sendo avaliado o desempenho dos animais. Esses autores observaram, em todas as propriedades analisadas, maior impacto no ganho de peso nos primeiros 28 dias após a castração, sendo que, em uma das fazendas avaliadas, $34,6 \%$ dos animais perderam peso neste período. De outro modo, Restle e Muehlmann (1993) não verificaram diferença no ganho de peso entre os bovinos castrados e não castrados no período de cicatrização, ou seja, nos primeiros 17 dias após a castração.

Lopes et al. (2012), ao mensurarem o desempenho dos bovinos não castrados por meio do ganho de peso total, observaram que esses animais foram $20,8 \%$ superiores aos animais castrados na terminação. Restle et al. (2000) avaliaram o consumo alimentar e o ganho de peso na fase de crescimento de animais não castrados ou castrados, dos grupos genéticos Charolês, Nelore e seus cruzamentos, e observaram maior ganho de peso dos bovinos não castrados em relação aos castrados. Isso porque os animais não castrados apresentam 
maior ganho médio diário e foram mais eficientes na transformação de alimento em ganho de peso que os castrados.

Para o ganho de peso médio diário (Tab. 1), observou-se que bovinos não castrados obtiveram maiores ganhos $\left(0,77 \mathrm{~kg} \mathrm{dia}{ }^{-1}\right)$ em relação aos castrados cirurgicamente $(0,35 \mathrm{~kg}$ dia $\left.{ }^{1}\right)$ com comportamento intermediário para os imunocastrados $\left(0,50 \mathrm{~kg} \mathrm{dia}^{-1}\right)$. Provavelmente, esse resultado é reflexo de o procedimento da castração cirúrgica ser considerado traumático, pois, mesmo sendo realizado por profissionais qualificados e com o uso de fármacos adequados, ocorreu comprometimento do desempenho animal nos primeiros 15 dias de avaliação póscastração. Nesse período, o organismo do bovino demanda mais energia consumida para converter no processo de cicatrização da incisão cirúrgica; com isso, o ganho de peso ficou comprometido em relação aos bovinos não castrados. De modo semelhante, no processo de imunocastração, ocorre a ativação da resposta imunológica no organismo do bovino, que pode ocasionar maior gasto energético, justificando o ganho de peso intermediário.

Os novilhos castrados cirurgicamente apresentaram maior frequência respiratória, 46,66 movimentos por minuto, em relação aos novilhos imunocastrados, 42,43 movimentos por minuto, e comportamento intermediário para os bovinos não castrados, os quais apresentaram 44,97 movimentos por minuto (Tab. 2). Entre as medidas fisiológicas diretas, estão aquelas decorrentes da ativação do sistema nervoso autônomo, como alterações das frequências cardíaca e respiratória (Bond et al., 2012). Numa situação de estresse, a estimulação simpática sinaliza para a liberação das catecolaminas (adrenalina e noradrenalina), as quais irão estimular todas as células que tiverem receptores adrenérgicos, preparando o organismo do animal para lutar ou fugir (Guyton e Hall, 2002). Contudo, os valores obtidos para os três tratamentos são considerados acima dos limites fisiológicos, entre 24 e 36 movimentos respiratórios por minuto, de acordo com Stöber (1993).

Tabela 2. Média e erro-padrão dos parâmetros fisiológicos e temperamentais de bovinos castrados cirurgicamente, imunocastrados e não castrados, nos primeiros 15 dias pós-castração

\begin{tabular}{|c|c|c|c|c|}
\hline \multirow{2}{*}{ Fisiológicos } & \multicolumn{3}{|c|}{ Condição sexual } & \multirow[b]{2}{*}{ Valor $\mathrm{P}^{1}$} \\
\hline & Castrado & Imunizado & Não castrado & \\
\hline Frequência respiratória, mov. $\min ^{-1}$ & $46,66 \pm 1,03^{\mathrm{a}}$ & $42,43 \pm 0,96^{\mathrm{b}}$ & $44,97 \pm 0,94^{\mathrm{ab}}$ & 0,0455 \\
\hline Frequência cardíaca, bat. $\min ^{-1}$ & $126,51 \pm 2,41^{\mathrm{a}}$ & $111,46 \pm 2,21^{\mathrm{b}}$ & $113,43 \pm 2,18^{\mathrm{b}}$ & 0,0033 \\
\hline Temperamentais & Castrado & Imunizado & Não castrado & \\
\hline Escore de balança, pontos & $2,25 \pm 0,13$ & $2,35 \pm 0,12$ & $2,01 \pm 0,12$ & 0,0783 \\
\hline Velocidade de fuga, $\mathrm{m} . \mathrm{s}^{-1}$ & $1,81 \pm 0,09$ & $1,68 \pm 0,08$ & $1,72 \pm 0,08$ & 0,4038 \\
\hline Distância de fuga, metros & $12,22 \pm 0,97^{\mathrm{a}}$ & $7,99 \pm 0,94^{\mathrm{b}}$ & $8,78 \pm 0,94^{\mathrm{b}}$ & 0,0234 \\
\hline
\end{tabular}

Para frequência cardíaca, os novilhos castrados cirurgicamente apresentaram 126,51 batimentos por minuto (bpm), superior aos resultados obtidos em bovinos não castrados ou imunocastrados, com valores de 111,46 e 113,43bpm, respectivamente (Tab. 2). Provavelmente, a avaliação dos parâmetros cardíacos em ambiente não habitual aos bovinos, o centro de manejo, e também o estresse ocasionado pelo período pós-operatório tenham influenciado nessas alterações, sendo essa resposta caracterizada pela soma de mecanismos de defesa animal (Ferreira, et al., 2006). De outro modo, Detweiler (1996) observou valores superiores e, portanto, descreve que bovinos apresentam frequência cardíaca entre 48 e 80 batimentos por minuto.

Os animais que não foram submetidos a procedimentos dolorosos, como os não castrados, mesmo assim, apresentaram parâmetros fisiológicos elevados, se comparados com os parâmetros normais de bovinos. Isso se deve ao manejo e ao ambiente diferente a que foram submetidos no momento da avaliação. Weary et al. (2006), quando avaliaram a resposta de animais não sujeitos à cirurgia, verificaram diferenças de comportamento, dos parâmetros fisiológicos e produtivos, mesmo na ausência de dor. 
Para as avaliações de escore de balança e velocidade de fuga, não foram observadas alterações entre bovinos castrados cirurgicamente, imunocastrados e não castrados nos primeiros 15 dias. A média do escore de balança foi de 2,20 pontos, considerado como animal inquieto, segundo a metodologia adaptada de Piovesan (1998). A média para velocidade de saída foi de 1,73 metros por segundo, considerando-se que quanto maior a velocidade de fuga, mais reativos tendem a ser os bovinos, conforme a metodologia de Burrow et al. (1988). Petherick et al. (2009) afirmaram que o tipo de contato humano-animal anteriormente experimentado por bovinos não influenciou na velocidade de saída.

A distância de fuga, caracterizada pela distância mínima a qual o animal permite aproximação do ser humano sem se deslocar, foi maior para os novilhos castrados cirurgicamente, ou seja, esses animais se deslocaram quando o avaliador estava a 12,22 metros de distância. Os bovinos imunocastrados e os não castrados apresentaram similaridade para essa variável, com valores de 7,99 e 8,78 metros, respectivamente. A maior reatividade dos novilhos castrados pelo método cirúrgico, possivelmente, está alicerçada na hipótese de memória visual do ambiente em que ocorreu a castração, que coincidiu com o local dessas avaliações, o centro de manejo.
O manejo sanitário dos bovinos compreendeu tanto o momento da realização da orquiectomia quanto o período pós-castração; assim, procurouse utilizar estratégias de manejo que possibilitem interações positivas entre o homem e o animal, a fim de se reduzir a associação negativa que o animal poderia fazer diante das lembranças visuais do centro de manejo. Petherick et al. (2009) ressaltam que as experiências vividas têm fundamental importância no comportamento dos animais em manejos futuros. Esses mesmos autores observaram que o medo em relação aos seres humanos (avaliado por teste de aproximação voluntária) foi influenciado pelo tipo de manipulação aplicada aos animais.

Nos últimos 25 dias de avaliação da póscastração, observou-se que o peso inicial e o final continuaram não apresentando diferença significativa (Tab. 3). Esse fato mostrou que, para as condições deste trabalho, as castrações cirúrgicas ou imunológicas não influenciaram nos pesos desses animais. Em conformidade com a presente pesquisa, Restle et al. (1994) avaliaram o peso de bovinos de corte não castrados ou castrados em diferentes idades e observaram que a castração aos 12 meses, como neste estudo, não influenciou nos pesos para as diferentes condições sexuais.

Tabela 3. Média e erro-padrão do desempenho de bovinos castrados cirurgicamente, imunocastrados e não castrados, nos 25 dias pós-cicatrização

\begin{tabular}{lcccc}
\hline \multicolumn{1}{c}{ Variáveis } & \multicolumn{3}{c}{ Condição sexual } & \multirow{2}{*}{ Valor P1 } \\
\cline { 2 - 4 } & Castrado & Imunizado & Não castrado & \\
\hline Peso inicial, kg & $280,04 \pm 9,01$ & $273,31 \pm 8,28$ & $281,53 \pm 7,98$ & 0,7556 \\
Peso final, kg & $307,74 \pm 9,30$ & $287,16 \pm 8,55$ & $301,74 \pm 8,24$ & 0,2482 \\
Ganho de peso total, kg & $27,70 \pm 2,12^{\mathrm{a}}$ & $13,84 \pm 1,95^{\mathrm{c}}$ & $20,21 \pm 1,88^{\mathrm{b}}$ & 0,0001 \\
Ganho médio diário, $\mathrm{kg}$ & $1,10 \pm 0,08^{\mathrm{a}}$ & $0,55 \pm 0,07^{\mathrm{c}}$ & $0,80 \pm 0,07^{\mathrm{b}}$ & 0,0001 \\
\hline
\end{tabular}

${ }^{\mathrm{a}, \mathrm{b}}$ Médias seguidas por letras diferente na linha diferem pelo teste $\mathrm{t}$ de Student $(\mathrm{P}<0,05) .{ }^{1} \mathrm{P}=\mathrm{Probabilidade}$.

Para o ganho médio diário de peso após transcorrido o período de cicatrização (Tab. 3), os novilhos castrados cirurgicamente apresentaram melhor ganho médio diário $(1,10 \mathrm{~kg})$, comparados aos bovinos não castrados $(0,80 \mathrm{~kg})$, e esses foram superiores aos imunocastrados, que apresentaram ganhos de peso diário de $0,55 \mathrm{~kg}$. Esse fato ocorreu devido à adaptação dos animais ao manejo e da sua recuperação do período traumático da castração cirúrgica. Bretschneider (2005) relatou que a castração cirúrgica realizada após a puberdade tem importante efeito no desempenho dos animais, o qual se estende por período superior aos 30 primeiros dias após a castração. No presente trabalho, nota-se que o ganho médio diário dos bovinos, após transcorrido o período de cicatrização do procedimento cirúrgico, foi compensatório ao baixo desempenho no período de recuperação da orquiectomia, visto que, em momentos de dor e sofrimento, o apetite do animal fica suprimido (Haddad et al., 2002).

É importante salientar que o período crítico da castração teve duração de apenas 15 dias, o que 
deve estar associado aos cuidados de manejo, principalmente sanitários, empregados no período de recuperação da orquiectomia. Assim, deve-se enaltecer a preocupação que todos os profissionais habilitados e os gestores rurais devem ter ao se realizar a castração em bovinos, pois os adequados cuidados pós-cirúrgicos mitigam as perdas produtivas, bem como auxiliam na aceitação pelos produtos de origem animal, em virtude dos cuidados com o bemestar animal.

Na comparação de bovinos não castrados com imunocastrados, percebe-se a superioridade dos não castrados em $45 \%$ para ganho médio diário. Resultado semelhante foi encontrado por Andreo et al. (2013), os quais observaram que bovinos não castrados apresentaram superioridade de $16,04 \%$ na comparação com os imunocastrados. No ganho de peso total (Tab. 3), foi observada diferença significativa, tendo novilhos castrados cirurgicamente apresentado maior ganho de peso (27,70kg), comparado com os não castrados $(20,21 \mathrm{~kg})$, e esses foram superiores aos imunocastrados, que tiveram ganho de peso de $13,84 \mathrm{~kg}$. Esse resultado acompanhou o ganho médio diário de peso, pois os novilhos castrados cirurgicamente estavam recuperados do póscirúrgico, no qual provavelmente as dores sentidas inicialmente estavam diminuídas, e, assim, restabeleceram seus padrões de pastejo e, consequentemente, ganharam mais peso.

Quando avaliados os últimos 25 dias póscicatrização, observa-se que as frequências cardíaca e respiratória não se modificaram entre os tratamentos, o que deve estar relacionado ao fato de os bovinos estarem acostumados com o manejo repetitivo, aos quais foram submetidos, assim como deve estar reduzido o estresse póstraumático da castração.

Não foi observada diferença para escore de balança entre as condições sexuais estudadas, sendo a média de 1,51 ponto, que é considerada "animais calmos", segundo a metodologia adaptada de Piovesan (1998). A média do segundo subperíodo foi inferior à observada no primeiro subperíodo, em que os animais encontravam-se inquietos. Isso é decorrente do fato de os bovinos estarem menos reativos e habituados ao manejo e ao ambiente.

A distância de fuga foi semelhante para as diferentes condições sexuais estudadas, o que está relacionado à melhor interação entre humanos e animais durante as realizações dos manejos, pois, no período pós-cicatrização, os bovinos não foram submetidos a procedimentos de vacinação. Silveira et al. (2008) relatam que a redução na reatividade está associada à rotina do manejo e ao processo de habituação com os humanos.

A velocidade de fuga apresentou diferença entre as condições sexuais (Tab. 4), visto que novilhos castrados cirurgicamente e imunocastrados apresentaram maior velocidade quando comparados com os bovinos não castrados, com valores de 1,64; 1,51 e 1,27m. s ${ }^{-1}$, respectivamente. Essa maior velocidade dos bovinos castrados cirurgicamente ou imunologicamente deve estar relacionada à interação entre animal-ambiente, pois, mesmo que os animais fossem submetidos a manejos aversivos, a memória dos animais ao local fez com que esses se propusessem a sair mais rapidamente das situações (contenção) em que se encontravam. Cabe ressaltar que os valores de velocidade de fuga no período pós-cicatrização foram inferiores aos do primeiro subperíodo, o que se deve ao fato de os animais estarem se adaptando ao manejo e atenuando sua reatividade.

Práticas de rotina, como vacinação, marcação e castração, são aversivas e conduzem a respostas negativas, com o aumento do nível de medo dos animais pelos humanos, o que eleva a distância de fuga e dificulta o manejo. Os resultados de Grandin (2000) confirmam que o animal pode desencadear uma resposta emocional, que se manifesta por mudanças comportamentais, provocando alterações fisiológicas, denominadas genericamente de estresse. No entanto, nesta pesquisa, os animais eram manejados de forma tranquila, dessa forma a distância de fuga apresentou redução em resposta às boas condições dadas aos bovinos. 
Tabela 4. Média e erro-padrão dos parâmetros fisiológicos e temperamentais de bovinos castrados cirurgicamente, imunocastrados e não castrados, , nos últimos 25 dias pós-cicatrização

\begin{tabular}{|c|c|c|c|c|}
\hline \multirow{2}{*}{ Fisiológicos } & \multicolumn{3}{|c|}{ Condição sexual } & \multirow{2}{*}{ Valor $\mathrm{P}$} \\
\hline & Castrado & Imunizado & Não castrado & \\
\hline Frequência respiratória, bat. $\min ^{-1}$ & $43,67 \pm 1,62$ & $43,71 \pm 1,54$ & $43,81 \pm 1,51$ & 0,7586 \\
\hline Frequência cardíaca, mov. $\min ^{-1}$ & $102,38 \pm 3,44$ & $100,31 \pm 3,44$ & $103,86 \pm 3,32$ & 0,9897 \\
\hline Temperamentais & Castrado & Imunizado & Não castrado & \\
\hline Escore de balança, pontos & $1,69 \pm 0,11$ & $1,43 \pm 0,11$ & $1,42 \pm 0,11$ & 0,2443 \\
\hline Velocidade de fuga, $\mathrm{m} . \mathrm{s}^{-1}$ & $1,64 \pm 0,12^{\mathrm{a}}$ & $1,51 \pm 0,12^{\mathrm{a}}$ & $1,27 \pm 0,12^{\mathrm{b}}$ & 0,0076 \\
\hline Distância de fuga, metros & $7,84 \pm 0,63$ & $6,34 \pm 0,57$ & $6,89 \pm 0,56$ & 0,1645 \\
\hline
\end{tabular}

${ }_{\mathrm{a}, \mathrm{b}}$ Médias seguidas por letras diferente na linha pelo teste de Kruskal-Wallis. ${ }^{1} \mathrm{P}=$ Probabilidade.

Embora a avaliação do temperamento seja complexa, em virtude de seus métodos de avaliação, da interpretação de seus resultados e dos vários fatores que afetam sua expressão, como: herdabilidade, genética, manejo, ambiente e também características inerentes ao animal, a sua adoção em sistemas criatórios de bovinos é importante, pois tem impacto significativo na eficiência produtiva. Assim, deve-se empregar o máximo de atenção na produção de bovinos de corte, pois manejos errôneos no sistema produtivo podem comprometer as aplicações zootécnicas. Isso porque a adoção de protocolos nutricionais, genéticos e ambientais devem estar associados à adoção de boas práticas de manejo, com destaque para a qualidade dos produtos obtidos, assim como para a excelência na preocupação com o bem-estar animal.

\section{CONCLUSÕES}

Os efeitos da castração cirúrgica, em curto prazo (primeiros 15 dias pós-castração), prejudicam o ganho médio diário de peso, assim como os bovinos submetidos a esse procedimento apresentam maior reatividade, com alteração de seus parâmetros fisiológicos e temperamentais, em comparação com bovinos não castrados. Entretanto, transcorrido o período de cicatrização, essas diferenças são mitigadas, com recuperação no ganho de peso e atenuação dos parâmetros fisiológicos e temperamentais de bovinos castrados cirurgicamente, em relação aos não castrados.

\section{AGRADECIMENTOS}

O presente trabalho foi realizado com apoio da Coordenação de Aperfeiçoamento de Pessoal de Nível Superior - Brasil (CAPES) - Código de financiamento 001.

\section{REFERÊNCIAS}

ANDREO, N.; BRIDI, A.M.; TARSITANO, M.A.; PERES, L.M. et al. Influência da imunocastração (Bopriva $\left.{ }^{\circledR}\right)$ no ganho de peso, características de carcaça e qualidade da carne de bovinos Nelore. Semin. Ciênc. Agrár., v.34, p.4121-4132, 2013.

BOIVIN, X.; LE NEINDRE, P.; CHUPIN, J.M. Establishment of cattle-human relationships. Appl. Anim. Behav. Sci., v.32, p.325-335, 1992.

BOND, G.B.; ALMEIDA, R.; OSTRENSKY, A.; MOLENTO, C.F.M. Métodos de diagnóstico e pontos críticos de bem-estar de bovinos leiteiros. Ciênc. Rural, v.42, p.1283-1293, 2012.

BRASIL. Conselho Federal de Medicina Veterinária. Resolução $n^{\circ} 877$, de 15 de fevereiro de 2008. Dispõe sobre os procedimentos cirúrgicos em animais de produção e em animais silvestres; e cirurgias rutilantes em pequenos animais e dá outras providências. Diário Oficial da União, Brasília, DF, 19 de março de 2008. Seção 1, p.173-174.

BRETSCHNEIDER, G. Effects of age and method of castration on performance and stress response of beef male cattle: a review. Livest. Prod. Sci., v.97, p.89100, 2005.

BURROW, H.M.; SEIFERT, G.W.; CORBET, N.J. A new technique for measuring temperament in cattle. Aust. Soc. Anim. Prod., v.17, p.154-157, 1988.

CARVALHO, F.S.R.; SILVA, C.R.; HOE, F. Impacto da castração cirúrgica no ganho de peso e estado clínico de bovinos de corte. Hora Vet., v.179, p.18-21, 2011.

COETZEE, J.F. Assessment and management of pain associated with castration in cattle. Vet. Clin. N. Am. Food Anim. Pract., v.29, p.75-101, 2013.

DETWEILER, D. Regulação cardíaca. In: REECE, S. Dukes - fisiologia dos animais domésticos, 11.ed. Rio de Janeiro: Guanabara Koogan, 1996. cap.9, p.157169. 
FERREIRA, J. J.; BRONDANI, I. L.; LEITE, D. T.; RESTLE, J.; ALVES FILHO, D. C.; MISSIO, R. G.; HECK, I.; SEGABINAZZI, L. R. Características da carcaça de tourinhos Charolês e mestiços Charolês $\mathrm{x}$ Nelore terminados em confinamento. Ciênc. Rural, Santa Maria, v.36, n.1, p.191-196, 2006.

GEARY, T.W.; WELLS, K.J.; AVILA, D.M; AVILA, J. et al. Effects of immunization against luteinizing hormone-releasing hormone and treatment with trenbolone acetate on reproductive function of beef bulls and steers. J. Anim. Sci., v.89, p.2086-2095, 2011.

GRANDIN, T. Livestock handling and transport. Wallingford: CABI Publishing, 2000. p.63-85.

GUYTON, A.C.; HALL, J.E. Tratado de fisiologia médica. 11.ed. Rio de Janeiro: Guanabara Koogan, 2002. p.1128.

HADDAD, J.J.; SAADÉ, N.E.; SAFIEHGARABEDIAN, B. Cytokines and neuro-imuneendocrine interactions: a role for the hypothalamicpituitary-adrenal revolving axis. J. Neuroimnol., v.133, p.1-19, 2002.

LAZZERI, L. Técnica operatória em veterinária. Belo Horizonte: UFMG, 1994. p.415.

LOPES, L.S.; LADEIRA, M.M.; MACHADO NETO, O.R.; PAULINO, P.V.R. et al. Características de carcaça e cortes comerciais de tourinhos Red Norte e Nelore terminados em confinamento. Rev. Bras. Zootec., v.41, 2012.

MATTA, M.V.R.; SILVA, R.C.M.; KNACKFUSS, F.B.; YASMIN, G.P. et al. Comparação entre técnica de castração cirúrgica e Burdizzo no ganho de peso de bovinos em sistema extensivo. Rev. Acad. Ciênc. Anim., v.15, p.175-176, 2017.

MOLETTA, J.L.; NUNES DO PRADO, I.; FUGITA, C.A.; EIRAS, C.E. et al. Características da carcaça e da carne de bovinos não-castrados ou castrados terminados em confinamento e alimentados com três níveis de concentrado. Semin. Ciênc. Agrár., v.35, p.1035-1049, 2014.

MOTT, G.O.; LUCAS, H.L. The design, conduct and interpretation of grazing trials on cultivated and improved pastures. In: INTERNATIONAL GRASSLAND CONGRESS, 6., 1952. Pennsilvania. Proceedings... Pennsilvania: State College Press, 1952. p.1380-1395.
PETHERICK, J.C.; DOOGAN, V.J.; HOLROYD, R.G.; OLSSON, P. et al. Quality of handling and holding yard environment, and beef cattle temperament: 1. Relationships with flight speed and fear of humans. Appl. Anim. Behav. Sci., v.120, p.1827, 2009.

PIOVESAN, U. Análise de fatores genéticos $e$ ambientais na reatividade de quatro raças de bovinos de corte ao manejo. 1998. 51f. Dissertação (Mestrado em Zootecnia) - Faculdade de Ciências Agrárias e Veterinárias, Universidade Estadual Paulista, Jaboticabal, SP.

RESTLE, J.; ALVES FILHO, D.C.; FATURI, C. et al. Desempenho na fase de crescimento de machos bovinos inteiros ou castrados de diferentes grupos genéticos. Rev. Bras. Zootec., v.29, p.1036-1043, 2000.

RESTLE, J.; GRASSI, C.; FEIJÓ, G.L.D. Evolução do peso de bovinos de corte inteiros ou castrados em diferentes idades. Pesqui. Agropecu. Bras., v.29, p.1631-1635, 1994.

RESTLE, J.; MUEHLMANN, L. Ganho de peso de terneiros de diferentes grupos genéticos no período imediatamente após a castração. Semin. Ciênc. Agrár., v.14, p.9-11, 1993.

SILVA, B.; POLETI, M.D.; MONCAU, C.T.; ROSA, A.F. et al. Neuroendocrine, metabolic and meat quality traits in castrated and non-castrated Nellore cattle. Ciênc. Rural, v.44, p.904-910, 2014.

SILVEIRA, I.D.B.; FISCHER, V.; WIEGAND, M.M. Temperamento em bovinos de corte: métodos de medida em diferentes sistemas produtivos. Arch. Zootec., v.57, p.321-332, 2008.

STÖBER, M. Identificação, anamnese, regras básicas da técnica de exame clínico geral. In: DIRKSEN, G.; GRÜNDER, H.D.; STÖBER, M. (Eds.). Exame clínico dos bovinos. 3.ed. Rio de Janeiro: Guanabara Koogan, 1993. p.44-80.

WEARY, D.M.; NIEL, L.; FLOWER, F.C.; FRASER, D. et al. Identifying and preventing pain in animals. Appl. Anim. Behav. Sci., v.100, p.64-76, 2006.

WEBSTER, H.B.; MORIN, D.; JARRELL, V.; SHIPLEY, C. et al. Effects of local anesthesia and flunixin meglumine on the acute cortisol response, behavior, and performance of young dairy calves undergoing surgical castration. J. Dairy Sci., v.96, p.6285-6300, 2013. 